\title{
Outcomes of coaxial microincision cataract surgery versus conventional phacoemulsification surgery
}

\author{
Anu Malik', Smruti Ranjan Dethi', Yogesh Kumar Gupta', Alka \\ Gupta ${ }^{2}$ \\ ${ }^{1}$ Hindu Rao Hospital \& North Delhi Municipal Corporation Medical College, New \\ Delhi, India; ${ }^{2}$ Lala Lajpat Rai Memorial Medical College, Meerut, Uttar Pradesh, \\ India
}

\begin{abstract}
Aim: To compare surgical parameters and visual outcomes of coaxial microincision cataract surgery (MICS) with standard phacoemulsification.

Methods: A prospective randomized study was conducted on 60 eyes of 60 patients with age-related uncomplicated cataract who underwent: standard phacoemulsification surgery (30 eyes) i.e., Group 1, or coaxial MICS (30 eyes) i.e., Group 2. Intraoperative parameters were mean effective phacoemulsification power (EPP), effective phacoemulsification time (EPT), and total volume of balanced salt solution (BSS) used. Best-corrected visual acuity (BCVA) and surgically induced astigmatism (SIA) were evaluated pre- and postoperatively.

Results: Mean BCVA at 6 weeks was $0.04 \pm 0.07$ in Group 1 and $0.05 \pm 0.08$ in Group 2. No significant difference was observed in SIA between the two groups. Mean EPT was $29.80 \pm 3.67$ seconds in Group 1 and $31.93 \pm 4.08$ seconds in Group 2. The mean total EPP in Group 1 was $35.77 \pm 5.17 \%$, whereas it was $33.70 \pm 3.05 \%$ in Group 2. There was a significant statistical difference between mean EPP and EPT in the two groups. Mean total BSS volume used in Group 1 was $128.83 \pm 19.81 \mathrm{ml}$, whereas it was $139.33 \pm 13.57$ $\mathrm{ml}$ in Group 2.
\end{abstract}

Conclusion: Although EPT and BSS volume used were significantly higher in coaxial MICS, the postoperative results of the two techniques were comparable.

Keywords: coaxial microincision cataract surgery, conventional phacoemulsification, surgically induced astigmatism

\section{Introduction}

Cataract is the main cause of curable blindness worldwide, with the developing world accounting for approximately three-fourths of this type of blindness. ${ }^{1,2}$ There are 100 million eyes with cataract causing vision of $<6 / 60$ and this number is increasing due to population growth and increasing life expectancy. ${ }^{3}$

Correspondence: Dr. Anu Malik, H. No. 584, Sri Nagar, Hapur, Uttar Pradesh, India. E-mail: docanu.20@gmail.com 
Cataract surgery has evolved over the years from couching in the ancient era to phacoemulsification in the present era. In 1967, the introduction of phacoemulsification by Kelman represented the beginning of a revolution in cataract surgery that made it possible to abandon more invasive procedures. ${ }^{4}$ In particular, incision size decreased from $10.0 \mathrm{~mm}$ required for the intracapsular cataract extraction to $7.0 \mathrm{~mm}$ for extracapsular cataract extraction and ultimately to the small incisions (3.2 to $2.8 \mathrm{~mm}$ ) currently used for phacoemulsification., ${ }^{4,5}$

Microincision cataract surgery (MICS) was first described by Jorge Alio in 2002 as a new concept of cataract surgery based on bimanual technique, new tools, fluidics, and a novel surgical technique concept. ${ }^{6}$ Agarwal et al. ${ }^{7}$ and Tsuneoka et al. ${ }^{8}$ described in parallel this surgical approach to cataract surgery with other denominations such as Phaconit or bimanual phacoemulsification-aspiration.

MICS was originally developed as a bimanual technique, which had many disadvantages including a steep learning curve, anterior chamber instability due to leakage through two incision sites, and limitation in infusion due to small instruments. ${ }^{9}$ In addition, mechanical wound trauma can occur secondary to angular movement of the instruments through the tight incision sites. ${ }^{9}$ To overcome these problems, microcoaxial cataract surgery was developed. The main advantage of the newer technique is that it uses the same methods as the conventional method, but with the smaller incisions; thus, the learning curve is less steep. ${ }^{10,11}$

MICS has many advantages. It reduces surgically induced astigmatism (SIA), intraoperative and postoperative inflammation, and the time required to recover visual function. ${ }^{12,13}$ In addition, because MICS requires a smaller wound and decreased tissue healing, the possibility of postoperative leakage and endophthalmitis is also decreased. ${ }^{14}$

This study was conducted to evaluate the outcomes of coaxial MICS with standard phacoemulsification with respect to intraoperative and postoperative outcomes in a matched group of patients, i.e., to compare the surgical parameters of coaxial MICS with standard phacoemulsification surgery and to assess and compare the relation of visual outcomes and SIA between the two surgical techniques.

\section{Materials and methods}

The prospective, randomized interventional study was conducted on 60 patients having significant cataract who attended the outpatient Department of Ophthalmology at Hindu Rao Hospital in New Delhi, India. Informed consent was taken from the patients participating in the study.

The patients were randomized in two groups of 30 patients each. Group 1: standard phacoemulsification (30 eyes).

Group 2: coaxial MICS (30 eyes). 
The inclusion criteria were: age > 40 years; either sex; uncomplicated senile cataract with grade II and III nuclear sclerosis; preoperative astigmatism of 1.5 dioptres or less; and consent and willingness for follow-up.

The exclusion criteria were patients having: lid abnormalities (ectropion, entropion, lagophthalmos, trichiasis); poor tear film status; active inflammation; lacrimal sac disorder; preoperative astigmatism more than 1.5 dioptres cylinder; corneal opacity, dystrophy or any other pathology; subluxated lens or zonular dehiscence; hypermature senile cataract, nuclear sclerosis greater than grade IV, and traumatic cataract; preoperative mydriasis less than $5 \mathrm{~mm}$; any evidence of glaucoma, uveitis, or retinopathy; systemic illness such as diabetes mellitus, hypertension, or tuberculosis.

A detailed history of patients was taken. Uncorrected visual acuity (UCVA) was estimated using the standardized Snellen chart or 'E' chart. Slit lamp grading of nuclear sclerosis was done using Lens Opacities Classification System III (LOCS III). Intraocular pressure was measured using an applanation tonometer, syringing. Keratometry was done along with estimation of axial length and intraocular lens (IOL) power by using an ultrasonic biometer. Fundoscopy was done to rule out any posterior segment pathology.

\section{Surgical procedure}

The procedure was thoroughly explained to the patient with its advantages and disadvantages. Patients were advised to use an antibiotic (moxifloxacin 0.5\%) with a non-steroidal anti-inflammatory agent (NSAID, ketorolac tromethamine $0.4 \%$ ) four times per day starting two days before surgery.

Surgery was performed under adequate mydriasis with $1 \%$ tropicamide and $10 \%$ phenylephrine two to three times before surgery. All patients were operated under peribulbar anaesthesia by a single surgeon. The Oertli System and coaxial MICS phacoemulsification tip and sleeve from the same manufacturer were used for phacoemulsification.

\section{Group 1}

Standard phacoemulsification (i.e., phacoemulsification tip with sleeve) through a $3.2 \mathrm{~mm}$ clear corneal incision was performed using the stop-and-chop nucleotomy technique. A flexible hydrophilic acrylic IOL with $5.5 \mathrm{~mm}$ optics was then implanted using an injector system after inflating the capsular bag with viscoelastic.

\section{Group 2}

Coaxial MICS (i.e., a sleeved thinner phacoemulsification tip) through a $1.8 \mathrm{~mm}$ incision was performed using the stop-and-chop nucleotomy technique. A flexible hydrophilic acrylic IOL with $5.5 \mathrm{~mm}$ optics was then inserted with an injector system after inflating the capsular bag with viscoelastic. 
The following intraoperative parameters were assessed for all patients:

1. effective phacoemulsification time (EPT);

2. mean total phacoemulsification percentage;

3. total balanced salt solution (BSS) volume (initial volume in infusion bottle minus residual BSS volume); and

4. intraoperative complications such as wound burns, hydration of wound, posterior capsule ruptures, and IOL damage and decentration.

Topical combined drops (prednisolone acetate $1 \%$ and gatifloxacin $0.3 \%$ ) every 4-6 hours/day for 4 weeks, topical lubricant (carboxymethyl cellulose 0.5 times/ day for 4 weeks, topical NSAID drops (ketorolac tromethamine $0.5 \%$ ) 3 times/day for 4 weeks, and topical cycloplegics (tropicamide 1\%) twice/day for 2 weeks were given postoperatively.

All patients who had undergone surgery were regularly followed-up. Their postoperative visual acuity was recorded by means of Snellen's chart. Visual acuity and keratometry were assessed for all patients on 1 day, 1 week, 2 weeks, 4 weeks, and 6 weeks postoperatively. SIA was calculated by subtraction method.

Preoperative $\mathrm{K} 1=$ Vertical meridian

$\mathrm{K} 2=$ Horizontal meridian

$\mathrm{K} 1-\mathrm{K} 2=\mathrm{K}$ (Preoperative astigmatism)

Similarly, postoperative K1 and K2 were also taken.

$\mathrm{K} 1 *$ (Postoperative) $-\mathrm{K} 2 *$ (Postoperative) $=\mathrm{K}^{*}$ (Postoperative astigmatism)

SIA was calculated by subtraction of preoperative astigmatism from postoperative astigmatism without assigning any sign.

\section{Statistical analysis}

Statistical testing was conducted with Statistical Package for the Social Sciences (SPSS) v.17.0. Continuous variables are presented as mean \pm SD, and categorical variables are presented as absolute numbers and percentages. The comparison of normally distributed continuous variables between the groups was performed using Student's t-test. General linear model repeated measure analysis was used to know the trend over time. Nominal categorical data between the groups were compared using the Chi-squared test or Fisher's exact test, as appropriate. A P-value less than 0.05 was considered statistically significant.

\section{Observations and results}

In Group 1, the oldest patient was 80 years old and the youngest was 48 years old; the maximum number of patients was in the age group of 51-60 years. In Group 2, the oldest patient was 72 years old and the youngest was 45 years old; the maximum number of patients was in the age group of 61-70 years. The mean age of the patients in Group 1 was $64.4 \pm 7.10$ years, while in Group 2 it was 58.8 
\pm 6.96 years. The age distribution between the two groups is shown in Table 1 . There were 16 (53.3\%) males and 14 (46.7\%) females in Group 1, and 11 (36.7\%) males and 19 (63.3\%) females in Group 2. There were 13 (43.3\%) grade II and 17 $(56.7 \%)$ grade III cataract patients in each group.

Table 1. Age distribution in Group 1 and Group 2

\begin{tabular}{|l|l|l|l|l|l|}
\hline \multirow{2}{*}{$\begin{array}{l}\text { Age (in } \\
\text { years) }\end{array}$} & \multicolumn{2}{|l|}{ Group 1 } & Group 2 & \multirow{2}{*}{ P-value } \\
\cline { 2 - 5 } & Frequency & $\%$ & Frequency & $\%$ & \\
\hline$\leq 50$ & 3 & $10.0 \%$ & 6 & $20.0 \%$ & \multirow{2}{*}{0.188} \\
\hline $51-60$ & 13 & $43.3 \%$ & 10 & $33.3 \%$ & \\
\hline $61-70$ & 9 & $30.0 \%$ & 13 & $43.3 \%$ & \\
\hline $71-80$ & 5 & $17 \%$ & 1 & $3.3 \%$ & \\
\hline Total & $\mathbf{3 0}$ & $\mathbf{1 0 0 \%}$ & $\mathbf{3 0}$ & $\mathbf{1 0 0} \%$ & \\
\hline
\end{tabular}

Group 1: standard phaco; Group 2: coaxial MICS

Preoperative intraocular pressure in Group 1 was $14.67 \pm 2.19 \mathrm{mmHg}$, whereas in Group 2 it was $15 \pm 2.02 \mathrm{mmHg}$.

Twelve (40\%) patients had visual acuity of 6/60 in Group 1, whereas $13(41.7 \%)$ cases had visual acuity of $6 / 60$ in Group $2 ; 13.33 \%$ cases in each group had vision $<6 / 60$.

The mean preoperative UCVA was $0.88 \pm 0.17$ in Group 1 and $0.90 \pm 0.15$ in Group 2, respectively, with no statistical difference. At 6 weeks postoperative follow-up, the mean best corrected visual acuity (BCVA) was $0.04 \pm 0.07$ in Group 1 and $0.05 \pm 0.08$ in Group 2. The difference between the two groups was not significant (Fig. 1).

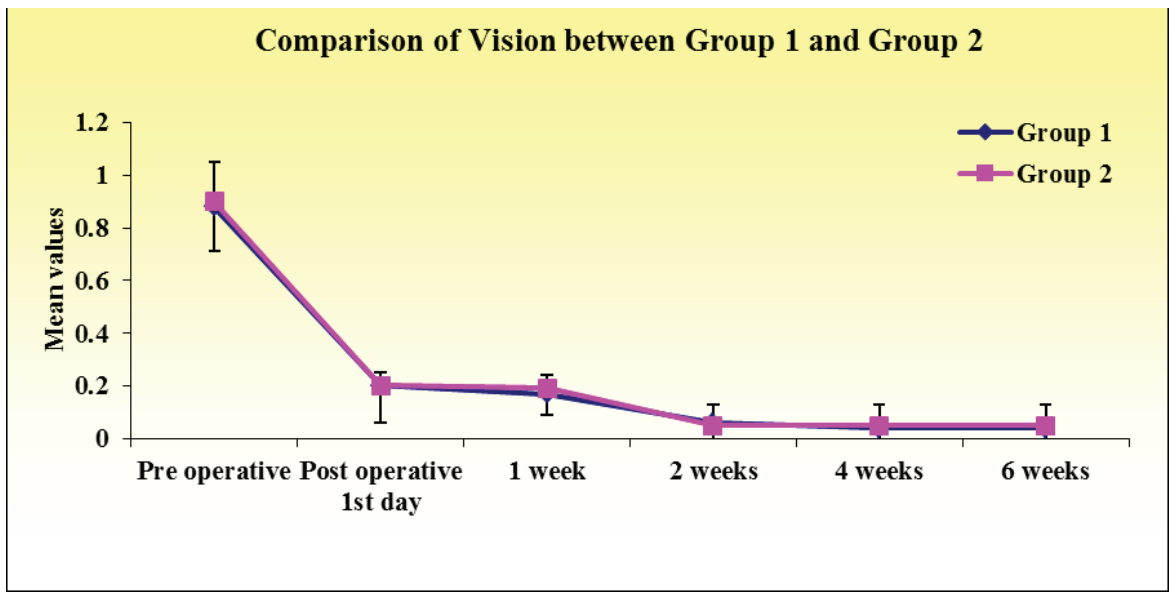

Fig. 1. Comparison of vision (BCVA in logMAR ) between Group 1 and Group 2. 
Preoperative mean K1 in Group 1 was $44.22 \pm 1.29$ D, whereas in Group 2 it was $44.25 \pm 1.33$ D. At 6 weeks postoperative, it was $43.15 \pm 0.89 \mathrm{D}$ in Group 1 and $43.66 \pm 1.37 \mathrm{D}$ in Group 2, respectively. The difference in these two groups was not clinically significant.

The mean K2 in Group 1 was $43.90 \pm 1.31$ D, whereas in Group 2 it was $43.86 \pm$ $1.31 \mathrm{D}$ preoperatively. At 6 weeks postoperative, it was $43.77 \pm 0.81 \mathrm{D}$ in Group 1 and $44.12 \pm 1.33 \mathrm{D}$ in Group 2, respectively. The difference in these two groups was not clinically significant.

It was observed that SIA changed gradually over the 6-week follow-up period (Table 2). Preoperative mean SIA in Group 1 was $0.54 \pm 0.37$, which changed to $1.20 \pm 0.76,1.05 \pm 0.73$, and $0.70 \pm 0.31$ at postoperative day 1, 1 week, and 6 weeks, respectively. Preoperative mean SIA was $0.49 \pm 0.33$ in Group 2, which changed to $0.82 \pm 0.60,0.62 \pm 0.45,0.58 \pm 0.37$ at postoperative day 1,1 week, and 6 weeks, respectively. The difference was significant at postoperative day 1 and 1 week in both the groups. At 6 weeks, the difference between the two groups was not clinically significant.

The mean total BSS used in Group 1 was $128.83 \pm 19.81 \mathrm{ml}$, whereas it was $139.33 \pm 13.57 \mathrm{ml}$ in Group 2 . The $\mathrm{p}$-value was 0.020 , which was statistically significant (Table 3).

The mean total phacoemulsification power (TPP) used in Group 1 was 35.77 $\pm 5.17 \%$; in Group 2 it was $33.70 \pm 3.05 \%$. The $p$-value was 0.027 , as there was a statistically significant difference found between the two groups (Table 4).

It was observed that the EPT in Group 1 was $29.80 \pm 3.67$ seconds, whereas in Group 2 it was $31.93 \pm 4.08$ seconds. The $p$-value was 0.037 and it was statistically significant (Table 5 and Fig. 2).

Table 2. Change in SIA (mean and SD of difference between K1-K2) in both groups pre- and postoperatively

\begin{tabular}{|l|l|l|l|}
\hline \multirow{2}{*}{ K1-K2 } & $\begin{array}{l}\text { Group 1 } \\
(\mathbf{n}=\mathbf{3 0})\end{array}$ & $\begin{array}{l}\text { Group 2 } \\
(\mathbf{n}=\mathbf{3 0})\end{array}$ & \multirow{2}{*}{ P Value } \\
\cline { 2 - 3 } & Mean + SD & Mean \pm SD & \\
\hline Preoperative & $0.54 \pm 0.37$ & $0.49 \pm 0.33$ & 0.585 \\
\hline Postoperative 1st day & $1.20 \pm 0.76$ & $0.82 \pm 0.60$ & 0.035 \\
\hline Postoperative 1 week & $1.05 \pm 0.73$ & $0.62 \pm 0.45$ & 0.007 \\
\hline Postoperative 2 weeks & $0.72 \pm 0.43$ & $0.58 \pm 0.38$ & 0.210 \\
\hline Postoperative 4 weeks & $0.73 \pm 0.35$ & $0.58 \pm 0.37$ & 0.109 \\
\hline Postoperative 6 weeks & $0.70 \pm 0.31$ & $0.58 \pm 0.37$ & 0.189 \\
\hline
\end{tabular}

Group 1: standard phaco; Group 2: coaxial MICS 
Table 3. Mean and SD of BSS volume used in Group 1 and Group 2

\begin{tabular}{|l|l|l|l|}
\hline & $\begin{array}{l}\text { Group 1 } \\
(\mathbf{n}=\mathbf{3 0})\end{array}$ & $\begin{array}{c}\text { Group 2 } \\
(\mathbf{n}=\mathbf{3 0})\end{array}$ & \multirow{2}{*}{ P-value } \\
\cline { 1 - 3 } & Mean \pm SD & Mean \pm SD & \\
\hline BSSV (in ml) & $128.83 \pm 19.81$ & $139.33 \pm 13.57$ & 0.020 \\
\hline
\end{tabular}

Group 1: standard phaco; Group 2: coaxial MICS

Table 4. Mean and SD of TPP used in Group1 and Group 2

\begin{tabular}{|l|l|l|l|}
\hline & $\begin{array}{l}\text { Group 1 } \\
(\mathbf{n}=\mathbf{3 0})\end{array}$ & $\begin{array}{l}\text { Group 2 } \\
(\mathbf{n}=\mathbf{3 0})\end{array}$ & \multirow{2}{*}{ P-value } \\
\cline { 1 - 3 } & Mean \pm SD & Mean \pm SD & \\
\hline TPP (in \%) & $35.77 \pm 5.17$ & $33.70 \pm 3.05$ & 0.027 \\
\hline
\end{tabular}

TPP: total phaco power; Group 1: standard phaco; Group 2: coaxial MICS

Table 5. Effective phaco time (EPT) in Standard phaco (Group 1) and coaxial MICS ( group 2)

\begin{tabular}{|l|l|l|l|}
\hline & $\begin{array}{l}\text { Group 1 } \\
(\mathbf{n}=\mathbf{3 0})\end{array}$ & $\begin{array}{l}\text { Group 2 } \\
(\mathbf{n}=\mathbf{3 0})\end{array}$ & \multirow{2}{*}{ P-value } \\
\cline { 1 - 3 } & Mean \pm SD & Mean \pm SD & \\
\hline EPT (in sec) & $29.80 \pm 3.67$ & $31.93 \pm 4.08$ & 0.037 \\
\hline
\end{tabular}

EPT: effective phaco time; Group 1: standard phaco; Group 2: coaxial MICS

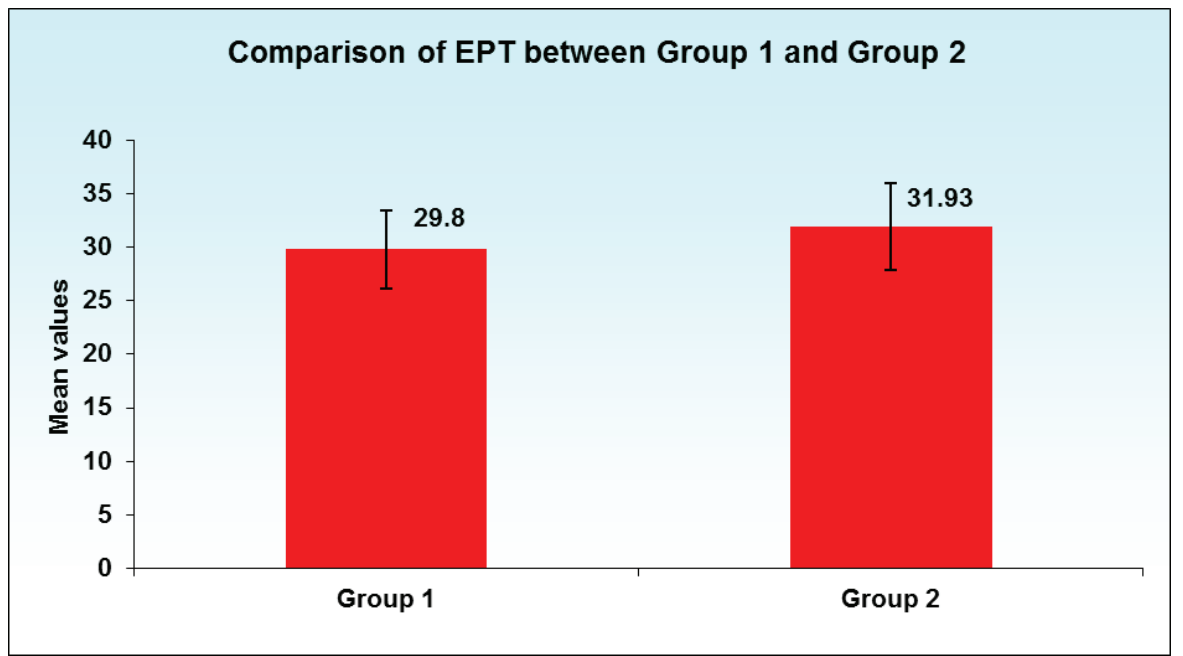

Fig. 2. Comparison of EPT between Group 1 and Group 2. 


\section{Discussion}

Coaxial microincision phacoemulsification has resulted from the interplay between microcorneal incisions, separation of functions, improved use of fluidics, rapidly progressing instrumentation, and low-energy phacoemulsification. ${ }^{6}$

We conducted a prospective randomized study in 60 eyes, which were randomly categorized to undergo either of the two surgeries with a 6-week follow-up. There was no statistically significant difference in the age groups for both groups. We selected cataracts from grades II to III and the cataract grades were similar in both groups; the difference between groups was not statistically significant.

Irrespective of their group, all patients showed significant improvement in visual acuity after surgery. In our study, the difference between the groups was not statistically significant at any of the follow-up visits ( $p>0.05$ ). In Group 1, 80\% achieved a BCVA of $6 / 6$ at 6 weeks; similarly, $83.33 \%$ had a BCVA of $6 / 6$ in Group 2.

Dosso et al. ${ }^{10}$, Alio et al. ${ }^{11}$, and Crema et al. ${ }^{16}$ found no significant difference in postoperative BCVA in coaxial MICS and conventional coaxial group. The findings in our study corroborate the findings of various studies in the literature. Kurz et al. showed that postoperative BCVA was found to be statistically better with MICS than standard phacoemulsification. ${ }^{15}$

In 1862, Donders et al. first described SIA. In the same year, Snellen suggested that placing the incision at a steeper axis would reduce the corneal astigmatism. ${ }^{17}$

In our study, there was statistically significant difference $(p<0.05)$ in SIA between the two groups at day 1 and 1-week follow-up period, but no significant difference at 2 weeks, 4 weeks, and 6 weeks follow-up visits.

A recent study reported no significant difference in SIA between the two microincision techniques; however astigmatic control is not the only requirement for faster visual rehabilitation. Trauma to corneal endothelial cells must also be minimized to ensure the best optical outcomes. ${ }^{18}$

MICS has the advantage of reducing SIA and that microincisions do not produce an increase in astigmatism compared with conventional $3 \mathrm{~mm}$ phacoemulsification. The shorter the incision, the less the corneal astigmatism, as it was estimated that the magnitude of SIA studied by vector analysis was around 0.44 and 0.88 $D$, increasing with increasing incision size. This is considered important because cataract surgery is progressively being considered a refractive procedure. Furthermore, small-incision surgery ( $3.5 \mathrm{~mm}$ incision without suture) does not systematically degrade the optical quality of the anterior corneal surface. Therefore, better results and fewer changes are to be expected with MICS (sub $2 \mathrm{~mm}$ incision).

Alio et al. ${ }^{11}$ demonstrated a statistically significant difference $(p<0.05)$ in SIA between the two groups at 1 month, 3 months, and 6 months follow-up period. However, such a difference was not seen in the comparative studies done by Dogru et al. ${ }^{19}$ and Wilczynska et al. ${ }^{20}$ 
In our study, we observed that there was a statistically significant difference in mean EPT between the two groups $(p<0.05)$. The study done by Dogru et al. ${ }^{19}$ did not show any significant difference in mean EPT. However, Alio et al. ${ }^{11}$ showed a lesser mean phacoemulsification time, total phacoemulsification percent, and EPT in the MICS group, whereas Dosso et al..$^{10}$ found statistically significant higher mean ultrasound time in coaxial MICS than in the conventional phacoemulsification group, which did not correlate with our study. Kurz et al. indicated a decrease in phacoemulsification time in the MICS group compared with coaxial surgery. ${ }^{15}$ Kahraman et al. showed a decrease in phacoemulsification time in the MICS group compared with the coaxial group $(p=0.001){ }^{20}$

Our study showed less power was used in coaxial MICS compared to standard phacoemulsification. There was a statistically significant difference found between the two groups ( $p$-value $=0.027$ ).

Alio et al. ${ }^{11}$ showed a large difference between the amounts of energy delivered into the eye. In MICS, phacoemulsification parameters were adjusted to overcome the possibility of wound burn and anterior chamber instability. The need for decreased power and vacuum was thought to be associated with increased EPT, average percentage power, phacoemulsification time, and surgery time. Saeed et al. found the average percentage power less with standard phacoemulsification $(\mathrm{P}<0.001) .^{22}$

Other studies by Mencucci et al., ${ }^{15}$ Kurz et al.., ${ }^{18}$ and Wilczynski et al. ${ }^{23}$ found no statistical differences between the two techniques. In a study comparing microincision $(2.2 \mathrm{~mm})$ versus standard $(2.8 \mathrm{~mm})$ clear corneal cataract surgery, mean cumulative dissipated energy was $6.64 \pm 3.82$ in the $2.8 \mathrm{~mm}$ incision group and $5.07 \pm 3.14$ in the $2.2 \mathrm{~mm}$ group; the difference was significant, but this could be attributed to the use of different phacoemulsification tip configurations between the two groups. ${ }^{24}$

In our study, there was a statistically significant difference between mean total BSS used in coaxial MICS and conventional coaxial cataract surgery. Dosso et al. ${ }^{10}$ and Alio et al. ${ }^{11}$ did not find any statistically significant difference between total BSS used in coaxial MICS and conventional coaxial cataract surgery.

No early intraoperative or postoperative event occurred that required a change in therapy. No eye showed signs of corneal thermal burn, zonular dehiscence, posterior capsular ruptures, $1 \mathrm{OL}$ decentration, $\mathrm{IOL}$ pigmentation, and IOL discoloration.

The main advantage of coaxial MICS is that it uses the same methods as the standard technique, but with smaller incisions. As the surgeon does not need to change their technique, the learning curve is short. There is currently a clear trend towards smaller incisions and discussion points to coaxial MICS as an ideal surgery technique due to having a short learning curve, better fluidics, 
same instrumentation, and the same IOL inserted through a sub-2 $\mathrm{mm}$ incision. Although the EPT and total BSS volume used were significantly higher in the coaxial MICS than in the standard phacoemulsification group, the postoperative results of the two techniques were comparable.

\section{References}

1. Thylefors B, Negrel AD, Pararajasegaram R, Dadzie KY. Global data on blindness. Bulletin World Health Organization. 1995;73:115-121.

2. Fletcher A, Kumar V, Selvaraj S. The Madurai Intra Ocular Study III: Visual functioning and quality of life outcomes. Am J Ophthalmol. 1998;125:26-35.

3. Kohnen S, Neuber R, Kohnen T. Effect of temporal and nasal unsutured limbal incisions on induced astigmatism after phacoemulsification. J Cataract Refract Surg. 2002;28:821-825.

4. Kelman CD. Phacoemulsification and aspiration; a new technique for cataract removal; a preliminary report. Am J Ophthalmol. 1967; 64:23-35.

5. Paton D, Ryan S. Present trends in incision and closure of cataract wound. Highlights Ophthalmol 1973;14:3-10.

6. Alió JL, Rodriguez-Prats JL, Galal A. Micro-incision cataract surgery. Highlights of Ophthalmology International: Miami, USA;2004.

7. Agarwal A, Agarwal A, Agarwal S, Narang P, Narang S. Phakonit: phacoemulsification through a $0.9 \mathrm{~mm}$ corneal incision. J Cataract Refract Surg. 200l; 27(10):1548-1552.

8. Tsuneoka H, Shiba T, Takahashi Y. Ultrasonic phacoemulsification using a $1.4 \mathrm{~mm}$ incision: clinical results. J Cataract Refract. Surg. 2002;28(1):81-86.

9. Weikert MP. Update on bimanual microincisional cataract surgery. Curr Opinion Ophthalmol. 2006;17:62-67.

10. Dosso AA, Cottet L, Burgener ND, Di Nardo S. Outcomes of coaxial microincision cataract surgery versus conventional coaxial cataract surgery. J Cataract Refract Surg. 2008;34:284-288.

11. Alio J, Rodriguez-Prats JL, Galal A, Ramzy M. Outcomes of microincision cataract surgery versus coaxial phacoemulsification. Ophthalmology. 2005;112(11):1997-2003.

12. Linebarger EJ, Hardten DR, Shah GK, Lindstrom RL. Phacoemulsification and modern cataract surgery. Surv Ophthalmol. 1999; 44:123-147.

13. Dick HB, Schwenn O, Krummenauer F, Krist R, Pfeiffer N. Inflammation after sclerocorneal versus clear corneal tunnel phacoemulsification. Ophthalmology. 2000;107:241-247.

14. Lundstrom M. Endophthalmitis and incision construction. Curr Opinion Ophthalmology. 2006;17:68-71.

15. Kurz S, Krummenauer F, Gabriel P. Biaxial microincision versus coaxial small incision clear cornea cataract surgery. Ophthalmology. 2006;113(10):1818-1826

16. Crema AS, Walsh A, Yamane Y, Nosé W. Comparative study of coaxial phacoemulsification and microincision cataract surgery, J Cataract Refract Surg. 2007;33:1014-1018.

17. FC Donders, WD Moore. On the anomalies of accommodation and refraction of the eye. London: New Sydenham Society; 1864.

18. Wilczynski M, Supady E, Piotr L, Synder A, Palenga-Pydyn D, Omulecki W. Comparison of surgically induced astigmatism after coaxial phacoemulsification through $1.8 \mathrm{~mm}$ microincision and bimanual phacoemulsification through $1.7 \mathrm{~mm}$ microincision. J Cataract Refract Surg. 2009;35:1563-1569.

19. Dogru $M$, Honda $R$, Omoto $M$, et al. Early visual results with the reliable ThinOptX intra ocular lens. J Cataract Refract Surg. 2004;30(3):558-565. 
20. Wilczyńska O, Wilczyński M, Omulecki W. Surgically induced astigmatism after bimanual phacoemulsification through microincision and after standard phacoemulsification.2010;112(4-6):115-119.

21. Kahraman G, Amon M, Franz C. Intraindividual comparison of surgical trauma after bimanual microincision and conventional small-incision coaxial phacoemulsification. J. Cataract Refract. Surg. 2007;33(4):618-622.

22. Saeed A, O'Connor J, Cunnife G. Uncorrected visual acuity in the immediate postoperative period following uncomplicated cataract surgery: bimanual microincision cataract surgery versus standard coaxial phacoemulsification. Int Ophthalmol. 2009;29(5):393-400.

23. Mencucci R, Ponchietti C, Virgili G. Corneal endothelial damage after cataract surgery: microincision versus standard technique. J. Cataract Refract. Surg. 2006;32(8):1351-1354.

24. Tanaka T, Koshika S, Usui M. Cataract surgery using the bimanual phacoemulsification technique with an Accurus system and Mackool microphaco tip. J Cataract Refract Surg. 2007;33:1770-1774. 